\title{
MEASURING THE TRANSPORTATION NEEDS OF PEOPLE WITH DEVELOPMENTAL DISABILITIES
}

\author{
Rania Wasfi \\ Research Fellow \\ University of Minnesota \\ 500 Pillsbury Drive S.E. \\ Minneapolis, MN 55455 \\ Phone: 612-624-8282 \\ Fax: 612-626-7750 \\ wasfir@umn.edu \\ David Levinson \\ Associate Professor, Civil Engineering \\ University of Minnesota \\ 500 Pillsbury Drive S.E. \\ Minneapolis, MN 55455 \\ Phone: 6126256354 \\ Fax: 6126267750 \\ dlevinson@umn.edu \\ Ahmed El-Geneidy \\ Post-doctoral Research Fellow \\ University of Minnesota \\ 500 Pillsbury Drive S.E. \\ Minneapolis, MN 55455 \\ Phone: 612-624-8282 \\ Fax: 612-626-7750 \\ geneidy@umn.edu
}

November 2006

Word Count $=5822+5$ 


\title{
MEASURING THE TRANSPORTATION NEEDS OF PEOPLE WITH DEVELOPMENTAL DISABILITIES
}

\begin{abstract}
The US Department of Health and Human Services Administration on Development Disabilities estimates the number of people diagnosed with a developmental disability in the United States as 4.5 million persons, which would translate to about 17,000 residents of Hennepin County, Minnesota. This research paper examines the transportation needs of adults with developmental disabilities either residing or working in Hennepin County through a survey of their existing travel behavior and their unmet transportation needs. The survey had both demographic and attitude questions as well as a travel diary to record both actual and desired but untaken trips. In this paper we report and discuss the main findings of the survey. It was clear from observing the returned sample that almost the entire surveyed population does not live independently. More than half of the surveyed population worked every day, while recreation occurred at least once a week for about two-thirds of the population, and more than half undertook social trips weekly. About $30 \%$ reported being unable to make trips they want to make and $46 \%$ unable to make trips they need to make. Public transit poses difficulties for this population both physically and intellectually. There were also specific complaints about the lack of transit service in addition to concerns regarding paratransit services. Community service providers received praise.
\end{abstract}

Key words: Developmental disability, disadvantaged population, disability, transportation needs 


\section{MEASURING THE TRANSPORTATION NEEDS OF PEOPLE WITH DEVELOPMENTAL DISABILITIES}

\section{INTRODUCTION}

Transportation systems are designed to serve communities by providing accessibility (the ability to reach valued destinations) and mobility (the ability to move on the network $(1,2)$. Limitation in mobility occurs when a person cannot move between an origin and a desired destination because of external or individual factors. People with limited mobility include but are not limited to senior citizens, the poor, children, persons who do not speak English, people with physical disabilities, and people with developmental disabilities. Limitation in mobility may affect physical, social, and psychological well-being. There is a growing recognition in the fields of disability services, rehabilitation, education and psychology of the need to promote selfindependence for individuals with mental retardation and developmental disabilities $(3,4$, 5). Transportation is considered one of the main means to determine the level of independence and self determination of PDD (6). Independence in transportation is a key towards achieving this goal.

This study investigates the travel demands and activities (in terms of both actual behavior and unmet needs) of people with developmental disability (PDD) residing or working in Hennepin County, Minnesota. The transportation needs were determined by conducting and analyzing a mail out -mail back survey that includes questions measuring the difficulty of reaching their desired destinations in the region to engage in some kind of activity (e.g. work, shopping, recreation, social, education, medical, agency support and businesses).

Only a few studies address the unmet needs of the transportation disadvantaged population. A literature search revealed that most researchers tend to use transportation options and modes as a mean to increase the independence of PDD yet none, to our knowledge, has documented the levels of independence or discussed the unmet needs of PDD.

Trying to understand the transportation needs of a special population such as PDD can be achieved through answering the following research question.

\footnotetext{
"What are the travel demands and activities (in terms of both actual behavior and unmet needs) of individuals with developmental disabilities?"
} 
This paper begins by defining developmental disabilities and mobility. It then reviews the (relatively scant) literature on the transportation needs of persons with developmental disability. This is followed by the research design, survey method, identification of research partners. The survey itself is described, its pilot testing explained. Next we present summary statistics, this is followed by more detailed analysis and discussion.

\section{DEFINITIONS}

Disability in the context of travel behavior research has no succinct definition. In a study conducted using data from the London Area Travel Survey, disability was defined as "a longstanding health problem that affects [a participant's] ability to travel or get about" (7). Meanwhile the Oregon Department of Transportation defines people with disability as "individuals of all ages who are unable to transport themselves without special equipment or outside assistance due to a physical, cognitive, or psychiatric impairment" (8). We define people with transportation disability in this research as people who cannot meet some or all of their transportation needs without the direct help of others. This definition is wide enough to include our population of interest.

This research paper concentrates on measuring the needs of people with developmental disabilities (PDD). Developmental disabilities (DD) are severe, chronic disabilities caused by mental and/or physical impairment. They typically appear before age 22 and last throughout a person's lifetime (9). The U.S. Department of Health and Human Services (HHS) reports that developmental disabilities result in substantial limitations in three or more of the following areas: self-care, receptive and expressive language, learning, mobility, self direction, capacity for independent living, and economic self-sufficiency. The HHS Administration on Development Disabilities estimates there are about 4.5 million persons with developmental disabilities in the United States (about 1.5\%), which would translate to about 17,000 residents of Hennepin County, Minnesota. Better understanding the transportation needs of PDD is crucial to address their needs, while classifying them should be based on the type of disability due to the variations in the types of DD (10).

This research aims to better understand the transportation needs and concerns of PDD as a special population. PDD have both met and unmet transportation needs. It is important to note that PDD as a population in general can include both transportation disadvantaged and advantaged people depending on the degree of disability and training.

The term transportation disadvantaged people in this paper refers to people who cannot meet all their transportation needs independently and require some special attention from the community to help them in meeting those needs. In contrast, the transportation advantaged can independently meet all their needs through the existing system. PDD can be trained to certain levels where they can partially overcome their disability and use public transit for example, to fulfill their transportation needs. Listening to the concerns of both advantaged and disadvantaged is important to help better serve their special needs.

Understanding these needs requires ascertaining two major pieces of information: the existing travel behavior patterns for the PDD population, and the unmet needs and wants of the relevant groups, e.g. what services they want but are not presently being provided. These provide a baseline of information to proceed with subsequent planning 
and decision-making. The perspective of the users of the services (and their caregivers) is critical to ensure an accurate measurement of both behaviors and desires.

The major types of developmental disabilities that the Center for Disease Control and Prevention (CDC) identifies on are: autism spectrum disorders, cerebral palsy, mental retardation, hearing loss, and vision impairment (9) This study by design excluded persons with only sensory impairment, which have been treated elsewhere, though the studies involving those groups are reviewed below. In this study the majority of the samples are people with mental retardation followed by cerebral palsy then other kinds of DD

It is generally acknowledged that there is a vital relationship between mobility and quality of life of PDD. However, because mobility is ill- or multiply-defined, this relationship is difficult to pin down. Mobility is often used synonymously with travel, but Metz (14) points out that a loss of mobility implies more of a hardship than does simply traveling less. Metz proposes operationalizing mobility using five key elements: Travel to reach desired people and places; Psychological benefits of movement - of "getting out and about"; Exercise benefits; Involvement in the local community; and Potential travel. Existing research tends to address the first of these, disregarding benefits that do not go hand-in-hand with a travel destination.

Previous studies on the travel behaviors of the people with disabilities have used a combination of categorical and operational ways of identifying the transportation disadvantaged population.

\section{LITERATURE REVIEW}

Most literature on travel needs and behaviors of people with disabilities has focused on people with physical disabilites some (an increasing amount) on those with sensory disabilities, very litlle of the literature has considered non-sensory developmental disabilities. Around $30 \%$ of people with hearing impairments or deaf and close to twothirds of children with vision impairment also have one or more other developmental disabilities (9). Although, hearing and vision impairments are not the focus of this study, the literature about them is germane

In a survey of bus users in Washington, DC and subway users in New York City, Winakur (11) found that the hearing impaired encountered problems with both bus and subway use. The problems experienced were mainly a result of difficulties in obtaining and using information about routes and fares and in communicating with the driver. For subway users, additional problems were encountered because people with hearing impairment were unable to hear loudspeaker announcements about emergencies or route changes and delays. Bettger \& Pearson (12) note similar problems in accommodating deaf and hard of hearing persons on buses, subways, and airplanes in Massachusetts, and make suggestions for improvements that could be made in each mode, from increasing awareness of telecommunication devices for the deaf (TDD) services to using video monitors and electronic readerboards to convey information.

Golledge, Costanzo, and Marston (13) surveyed blind and vision-impaired populations in Santa Barbara, California to determine how non-driving impacts their quality of life and what types of transportation are most used. Respondents were recruited through local agencies that deal with the visually impaired. 55 people participated via 
mail (large print) survey, telephone survey, and in-person interviews. Around $51 \%$ of the respondents identified the local bus as their primary mode of travel [not random], and the top reasons given for using public transit were the fact that service met their needs, cost, and lack of alternative. Other forms of transportation used included household cars, walking, friend's cars, and agency vans. Sixty-seven (67) percent of the sample depended on others for transportation, and four-fifths of these indicated frustration from this dependence. The authors noted some differences in activity patterns of the respondents from the sighted: Limited transit schedules constrained late-night and Sunday travel; participants needed assistance in traveling and, due to the necessity of living near a bus stop, choice of home location was restricted. Most participants were familiar with the range of services for people with disabilities in their community, and $58 \%$ felt these services met their needs.

\section{RESEARCH DESIGN}

The goal of this research is to measure the actual and un-met transportation needs of PDD residing or working in Hennepin County, Minnesota. Hennepin County is part of the Twin Cities seven counties region. The County consists of 46 cities including Minneapolis, Minnetonka, Maple Grove, Edina, Plymouth, Bloomington, Eden Prairie and Saint Louis Park.

Since this research deals with a special population, the available secondary datasets are not sufficient to help in reaching this goal, accordingly conducting a survey and collecting primary data that measures the needs of this population is essential. Based on a theoretical background the research team constructed a transportation survey that can help in achieving the main goal of this study. Targeting PDD to answer this questionnaire can be accomplished most readily through partnership with several disability organizations and the residential communities that are dedicated to serve them. In other words, reaching the targeted population is done through people who provide services to them, where mailing lists and contact information are maintained. This partnership started with the early stages of the study, where several partners helped in reviewing the survey or even organizing meetings with PDD to pilot test the survey. After the return of several surveys from the pilot testing, the research team incorporated several changes to the survey to address the concerns and issues being raised by PDD who were part of the testing. The survey was then distributed to PDD through various channels of communication depending on the type of partnership being established between the research team and the community partners. Finally surveys were returned to start the analysis phase. Figure 1 outlines the flow of the research.

\section{Population and Sampling Method}

The population of interest in this study comprises PDD residing or working in Hennepin County. For purposes of this study, the PDD will be defined as those who are diagnosed with autism spectrum disorder, cerebral palsy, and mental retardation and any other traumatic brain injuries that lead to a DD. This is a broad enough definition to 
include all the people defined by CDC (9) as PDD. In order to represent a diverse crosssection of PDD, the following characteristics are taken into account when selecting partners to recruit PDD to be part of the study:

- Geographic location: Hennepin County includes the urban core of Minneapolis as well as suburbs and distant exurbs. Each of these types of locations offers a different set of transportation options to the PDD.

- Recruitment of participants are chosen to be PDD that have degrees of mental retardation range from mild to profound., cerebral palsy (CP), autism spectrum disorder (ASDs) or any other type of DD that the community partners served. People with various levels of MR can be recruited to be part of the survey. $\mathrm{CP}$ is a motor impairment resulting from brain damage in the young child. Depending on which areas of the brain have been damaged, one or more of the following may occur:

- Muscle tightness or spasm

- Involuntary movement

- Disturbance in gait and mobility

- Abnormal sensation and perception

- Impairment of sight, hearing or speech

- Seizures (or convulsions) which are temporary abnormal electro physiologic phenomena of the brain, resulting in abnormal synchronization of electrical neuronal activity. The medical syndrome of recurrent, unprovoked seizures is termed epilepsy, but some seizures may occur in people who do not have epilepsy.

(ASDs) are a group of developmental disabilities that are caused by unusual brain development.

- Independence level: Mobility is not just a function of type and level of disability, but also of relative independence level. Independence, as a concept, encompasses physical and mental disabilities. Living situation will be used as a proxy for independence level. PDD who are hospitalized or in hospice care may not be medically stable, and the difficulties associated with incorporating their participation is probably too great for it to be worthwhile.

- Racial and ethnic diversity: Hennepin County is becoming a more diverse place in the year 2000, 21 percent of residents were non-white, up from 11 percent in 1990 , though much of that diversity is in the younger immigrant population. To be fully representative, the study includes PDD from a variety of racial and ethnic backgrounds. One barrier to this is language: $46 \%$ of the state's foreign-born population lives in Hennepin County. PDD foreign-born Hennepin County residents may not be proficient in English, and producing survey materials in alternative languages is beyond the scope of the study.

In order to account for all these elements of diversity, it was necessary to recruit participants from different sources. The most efficient way to recruit participants was to develop relationships with community partners, which include agencies and organizations that provide support to PDD and willing to allow and/or coordinate participant recruitment. 


\section{Community Partners}

Community partners play a very important role in connecting the research team with the PDD they serve. PDD centers, programs, community services which supervise PDD centers and transportation programs located in Hennepin County were chosen to be the community partners that helped us in conducting this study. The research team contacted around 12 disability organizations serving PDD in Hennepin County. Of the 12 contacted, 5 partners who are (Partnership Resources, Inc Rise, Inc, Opportunity Partners AccessAbility, Inc, and Arc Greater Twin Cities) agreed to help the research team in the study by either:

1. Introducing the study to a sample of PDD for pilot testing,

2. Distributing surveys at sites, and

3. Sending the surveys to PDD by mail through use of mailing lists.

It is important to note that our sampling is biased towards the cities and areas which PDD organizations or community services agreed to help us and to the level of support we received from these partners.

\section{Survey}

In order to ascertain the transportation needs of PDD the research team designed a survey that contains a set of quantitative and qualitative questions. The quantitative questions in the survey include standard information about demographic and socioeconomics characteristics (level of education, age, gender, income, housing, household information, and ethnicity). In addition, a set of questions is targeted towards identifying the transportation modes and frequency of usage to reach these activities. Travel/activity diary information recording every trip or activity undertaken by an individual over the course of the day is also included in the survey.

The qualitative questions are directed to the travel and activities that the PDD could and/or could not be undertake. Meanwhile a set of supporting questions are included to help in quantifying the reasons if any activity was not met and if the reason was due to a disability or the person's physical condition, or the location of the desired activities, and/or quality of existing transportation services or any other reasons. The main questions in the survey tried to cover the following areas:

- The frequency of trips made to different destinations,

- The two modes of transportation most used,

- If there is a need of assistance in traveling,

- Capability of making trips needed and /or wanted,

- The use of automobile,

- The use of paratransit,

- The use of public transit,

- Difficulty using public transit,

- Concerns using public transit,

- Attitudes using public transit,

- Attitudes towards driving (dependence/independence),

- Concerns related to transportation, and

- Demographic and socio economic questions. 
In addition two questions were added asking if the participant has any diagnosed medical condition or disability. An open ended question is included at the end of the survey for PDD to report any comments or concerns related to their transportation needs or limitations. This section helps in allowing the participants to raise topics and issues that are not covered in the survey. Another key question was asking who filled the survey the participant or someone else on behalf of him or her.

\section{Pilot Testing and Survey Distribution}

Since this research tries to capture the transportation needs of a special population, conducting a pilot test and getting feedback from a sample of PDD was essential. A group of PDD was used to assure that the questions proposed in the survey cover their transportation concerns. The PDD group was also used to test the ease of understanding the survey questions. Guardian approvals were obtained prior to the meeting. This meeting took place as part of the monthly leadership meeting at one of the PDD partners. The research team presented the survey and distributed it to the PDD attending the meeting. The pilot testing helped the research team finalize a survey that can capture the transportation needs (met and unmet) of PDD.

Ultimately 990 survey packets were prepared and printed for distribution to the partners. The survey packets included: Letter of invitation, survey, travel diary, trips you made today, trips you couldn't make today, consent form, assent form, and inserts from partners that explains the study and the support of the organization (that was optional). A copy of the survey packet is provided in the final report (15).

The distribution methods of the survey varied based on the agreement between the research team and the community partners. It was either mailed or handed to participants. Of the 990 survey packets that were printed and distributed. The research team received 124 returned envelopes of which 114 surveys were completed. The difference of 10 surveys came from PDD who did not want to participate in the study. Most of these cases the responses came mainly from the guardians stating that the targeted participant has severe degree of disability and his transportation needs are minor and being met by his family members. The total response rate was $11.51 \%$ for the survey and $9.49 \%$ for the travel diaries.

\section{DESCRIPTIVE STATISTICS}

It is important to note that the findings of this study only represent the characteristics of the people who received the surveys and responded to it. The majority of the returned surveys were filled by a guardian, relative, staff member, or volunteer on behalf of the subject. Only 16 surveys were filled by the PDD themselves. This number represents around $14 \%$ of the returned sample, while 15 returned surveys did not indicate how they were filled or by whom.

\section{Types of Development Disability}

Since the PDD is a unique and diverse population, the type of development disability will be used in this research as the main factor for classifying the results and the data. Two questions were used to determine the type of disability as mentioned earlier. The answers 
to these questions were classified into two main categories of development disability including: MR and others. The others category included answers as autism spectrum disorder, cerebral palsy, traumatic brain injuries, people with developmental disabilities, Noonan syndrome, multiple sclerosis, dependent personality disorder; various brain and nerve disorders, and people who answered that they would rather not discuss there type of disability. The reason for classifying the sample into MR and others category is because of the sample size that responded to the survey.

The CP and ASD comprised only $11 \%$ of the entire population accordingly they were merged in the analysis to the Others category. The responses from MR population was (49\%) A sample of 114 from a statistical standpoint may be considered small, yet when observing the type of population being studied such sample can be considered good enough to raise issues related to the needs of this small and disadvantaged population.

\section{Age and Gender}

Among the 114 returned surveys, 2 PDD did not report their age. Figure 2 shows the distribution of the PDD who responded to the survey by age group and type of disability. It is clear from observing Figure 2 that all age groups are presented in the total section. Approximately $56 \%$ of the responses came from males while around $43 \%$ came from females and one person refused to identify gender.

\section{Education}

Level of education and household income are two factors that tend to be highly correlated. The level of education that PDD have received is used as a proxy to understand their level of independency. Around 68\% of the PDD who answered this question reported that they had education at the level of high school. Meanwhile only $25 \%$ had an education at the less than high school level. Only a few reported any college education.

\section{Place of residence}

The place where PDD live can also be used as an indicator for the level of independence. In the survey two questions were directed towards understanding where PDD reside and if they live with a relative or a non-relative. Around 53\% of the total surveyed sample indicated that they live in a group facility. Meanwhile around $29 \%$ of the surveyed sample lives in private homes or condos, while $10 \%$ reside in apartments. The majority of PDD reside with non-relatives, while $25 \%$ lives with relatives. Around $8 \%$ of the surveyed sample resides by themselves in apartments, group facility and private condos. Two people indicated they reside by themselves in a group facility where they might be referring to their personal rooms in the facility where they do not share bedrooms with others. As expected it is clear that the level of independence in living arrangements tends to be low. 


\section{Travel Diaries}

The total number of returned travel diaries was 100 . Only 94 travel diaries were filled and included information related to trips. Around 19\% of the PDD who returned the surveys had (at least) four trips reported as part of their diary. Meanwhile $10 \%$ of the returned and filled diaries reported that three trips took place during the day the diary was recorded, while $44 \%$ reported doing only two trips during the same period of time. Finally $25 \%$ of the returned and filled diaries who had an activity reported one trip being made.

\section{ANALYSIS AND DISCUSSION}

This section concentrates on displaying the major findings of the survey. In order to better understand the transportation needs of the surveyed sample, looking at some questions while controlling the type of DD is critical to understand the general trends and if there is a specific phenomenon associated to a certain DD group.

\section{Trip Purpose}

Observing the purpose of the trip, in the travel diaries, PDD reported trips to work, home, social and recreation and others as the top four purposes for traveling. Trip chaining is noticed to be part of 34\% (26 observations) of the travel pattern among the surveyed sample who answered this section of the travel diaries (76 observations). This indicates that fair amount of PDD engage in various activities after leaving their place of origin. Accordingly the purpose of leaving their homes is not just to conduct one activity but to conduct various activities.

\section{Frequency of Trips}

Observing the frequency of being engaged in work trips in the survey shows that around 74 participants responded they usually engage in such activity at least five to seven days per week, while 18 participants indicated they get engage in work trips at least for two to four days per week. These two numbers comprise around $80 \%$ of the total surveyed population. This relationship is displayed in Figure 3. It is also noticed that this observation is especially true among the MR group we sampled. More than $90 \%$ of the MR group indicated they work at least 2 days per week. Figure 4 shows the frequency of being engaged in recreational trips, while Figure 5 shows the frequency of being engaged in a social trip. Comparing the distribution of frequency of being engaged in social and recreational trips to the frequency of being involved in work trips we notice PDD tend to do more social than recreational trips, though work remains the most frequent trip purpose.

\section{Travel Needs}

The survey asks the participants if there are times they cannot make trips they need to make and asks them if there are times they cannot make trips they want to make. Around 55 participants responded "No" they can make both the trips they want to make and the trips they need to make. This number represents $50 \%$ of the surveyed sample.

Meanwhile 29 participants responded yes they are facing problems in doing both the trips they need to make and the trips they want to make. Only $25 \%$ of the participants with 
MR had trips they needed to do but could not do. Similarly in the others group around $30 \%$ of the participants responded yes there are trips they need to but could not make.

\section{Travel Mode and Assistance}

Work and shopping are two main purposes for all persons and were noticed to be the major trips that PDD tend to be engaged in. Around 39\% of the surveyed sample uses private cars as their primary mode of transportation for shopping. The number of people using other modes, which includes local services at home facilities, is quite high along with the MR group. Around $70 \%$ of the surveyed sample reported a need for assistance when conducting shopping trips. Around $52 \%$ of the surveyed sample reported a need for assistance when conducting work trips.

\section{Difficulties}

A question in the survey concentrated on the difficulties participants face when using public transit. These questions concentrated mainly on the physical difficulties associated with moving, standing, waking to the bus stop, climbing stairs, and reading the route numbers. Among MR participants $46 \%$ face problems in standing.

From the total sample $46 \%$ of the participants indicated they face problems in reading schedules, while $49 \%$ indicated they face problems understanding schedules. Transit schedules in general are being written to time points. A user of the service not using a time point interpretations is required to determine the arrival and departure time. This way of writing schedules is even difficult for the general population to understand. Accordingly it is expected that PDD might face such issues. Difficulties in understanding the announcements being made on board of the bus were reported by $35 \%$ of the surveyed sample.

\section{Concerns of Transit Users}

Public transit was the second-most used mode of transportation for PDD. Around $51 \%$ of the surveyed sample reported that they are either concerned or very concerned that the bus service might not serve their destinations at their desired time. Meanwhile $55 \%$ were concerned with being a victim of a crime while using public transit. Fewer than $50 \%$ of the surveyed sample were concerned with transfers between various transportation systems during their trips.

\section{Familiarity with Services}

Around $75 \%$ of the surveyed sample indicated being familiar with services offered to PDD. Meanwhile around 25\% of the surveyed sample indicated that they are not familiar (disagree and strongly disagree) with the services being offered to PDD. This indicates that more work may be needed in promoting the services to PDD. It is clear that paratransit service is used by only $62 \%$ of the surveyed sample. It is important to note that restrictions do exist when applying for paratransit, for example dial-a-ride service and not all PDD are qualified for such service. It is observed that around $30 \%$ of the surveyed sample have used Metro Transit (the pubic transit authority in the Twin Cities) either buses or light rail at some point in time as a mode of transportation. The variation among the various PDD groups seems to be minor. 


\section{Independence}

Independence is measured directly through asking direct questions related to what extent PDD consider themselves as independent travelers. Around $48 \%$ of the participants in the survey reported that they do agree that they are independent travelers. Observing each PDD group we notice that the MR group feels least independent compared to the other PDD groups. The levels of independence of the other DD groups tend to be higher for the others group Surprisingly around $68 \%$ of the surveyed sample indicated it's their choice which mode of transportation they use. Finally a question related to public transit and the possibility of using it as a means of increasing the independence. Around $68 \%$ of the surveyed sample responded that they do agree that using public transit would increase their level of independence. The MR group tends to disagree more with this statement than other PDD.

\section{Travel Barriers}

The travel diaries included a question asking participants about the trips they could not make. Only 14\% percent of the 94 participants who filled the diaries reported at least one trip they could not make. Meanwhile $7 \%$ of the participants who filled travel diaries had at least two trips they wanted to make but they could not make them, while $4 \%$ of the participants could not make at least three trips they wanted to make. Finally only $3 \%$ of the participants who filled travel diaries had at least four trips they wanted to make but they could not make.

"No one available to drive" was the most widely cited reason why participants could not make their desired trips. Other reasons included: too late to make reservations, scooter battery died, weather, health, and service is too far to go to.

\section{CONCLUSION}

This paper presents the results of an 18 month research study into the transportation behavior and needs of PDD living or working in Hennepin County Minnesota. The paper describes previous research into the transportation behaviors of the disability, the methodology pursued in this study, and the findings and results of that study. Overall, most PDD responding to the surveys remain partially independent (around 48\%). This number might seem to be a little high for the PDD population in general, yet this might be related mainly to the characteristics of the studied sample.

Being auto passengers, walking, public transit, and dial-a-ride are found to be the main modes of transportation participants tend to use to meet their transportation needs. PDD in the surveyed sample showed a willingness to use public transit more and indicated that they feel that using it will increase their independence. Several PDD indicated their willingness to drive yet they cannot afford to do so due to their conditions. Also several participants would like to use public transit yet report service does not exist around their homes or near their destinations; they felt using it was not possible for the time being. Issues related to understanding and interpreting the schedules was also raised.

The needs of assistance are observed among almost half of the surveyed sample. Issues related to dial-a-ride services and complaints were a common factor in the comment sections. There was notable criticism of the long lead times for scheduling and 
unreliability of public paratransit services, though there was commendation for the paratransit provided by service providers directly.

Several participants added some comments related to the walking distance to and from bus stops. Various participants raised safety concerns. The sampling of the survey was determined based on the level of cooperation between the PDD centers and research team. The sample is biased towards the locations where these centers tend to serve their population. Since only $14 \%$ of the PDD filled the surveys themselves, this study should be interpreted carefully since it reflects a mix of points of views of the guardians or relatives, as well as the PDD. Still this study remains a unique in the transportation field in trying to study and measure the needs of a population that has had very little transportation research conducted about their needs. 


\section{References}

1. Handy, S. L., \& Niemeier, D. A. (1997). Measuring accessibility: An exploration of issues and alternatives. Environment and Planning A, 29(7), 1175-1194.

2. Hansen, W. (1959). How accessibility shapes land use. Journal of the American Institute of Planners, 25(2), 73-76.

3. Abery, B. (1994). A conceptual framework for enhancing self-determination. In M. F. Hayden \& B. H. Abery (Eds.), Challenges for a service system in transition (pp. 345380). Baltimore: Paul H. Brookes Publishers.

4. Brown, F., \& Gothelf, C. R. (1996). Self-determination for all individuals. In D. H. Lehr \& F. Brown (Eds.), People with disabilities who challenge the system (pp. 335353). Baltimore: Paul H. Brookes Publishers.

5. Crimmins, D. B., \& Berotti, D. (1996). Supporting increased self-determination for individuals with challenging behaviors. In D. H. Lehr \& F. Brown (Eds.), People with disabilities who challenge the system (pp. 379-402). Baltimore: Paul H. Brookes Publishers.

6. Wehmeyer, M.; Kelchner, K., \& Richards S. (1996) Essential Characteristics of Self Determined Behavior of Individuals With Mental Retardation. American Journal on Mental Retardation, Vol. 100(6), 632-642.

7. Schmöcker, J., Quddus, M. A., Noland, R. B., \& Bell, Michael G. H. (2005). Estimating trip generations of elderly and disabled people: An analysis of London data. 84th annual meeting of the transportation research board, Washington, DC, 121.

8. Oregon Department of Transportation. (1999). Oregon's mobility needs: General population survey and transportation provider survey No. FHWA-OR-RD-99-19). Salem, OR: Oregon Department of Transportation.

9. Centers for Disease Control. (2004). What are developmental disabilities? Retrieved February 2, 2005, from http://www.cdc.gov/ncbddd/dd/default.htm

10. U.S. Department of Health and Human Services (2005) Administration of development disability. Retrieved October 2, 2006, from http://www.acf.hhs.gov/programs/add/ 
11. Winakur, I. (1977). Transportation needs of deaf people: A study of the problems that deaf people encounter with use of public transportation in the washington, D.C., metropolitan area and new york city subway: Recommendations for local \& national solutions No. DOT-0S-50110). Washington, DC: Gallaudet College; U.S. Department of Transportation.

12. Bettger, G. R., \& Pearson, T. J. (1989). Accommodating deaf and hard-of-hearing persons on public transportation systems in massachusetts: A study. Boston: Massachusetts Executive Office of Transportation and Construction.

13. Golledge, R. G., Costanzo, C. M., \& Marston, J. R. (1996). The mass transit needs of a non-driving disabled population (California PATH Research Report No. UCB-ITSPRR-96-9)University of California- Santa Barbara.

14. Metz, D. H. (2000). Mobility of older people and their quality of life. Transport Policy, 7, 149-152.

15. Levinson,D.M , Wasfi, R.A. (2006) Studying the transportation disadvantaged:Elderly and Developmentally disabled, NEXUS Transportation research group, Minneapolis MN, http://rational.ce.umn.edu/Projects/Disadvantaged/Disadvantaged.html 


\section{List of Figures}

Figure 1: Research Design

Figure 2: Sample by Age Group

Figure 3: Frequency Work Trips

Figure 4: Frequency of Recreational Trips

Figure 5: Frequency of Social Trips 


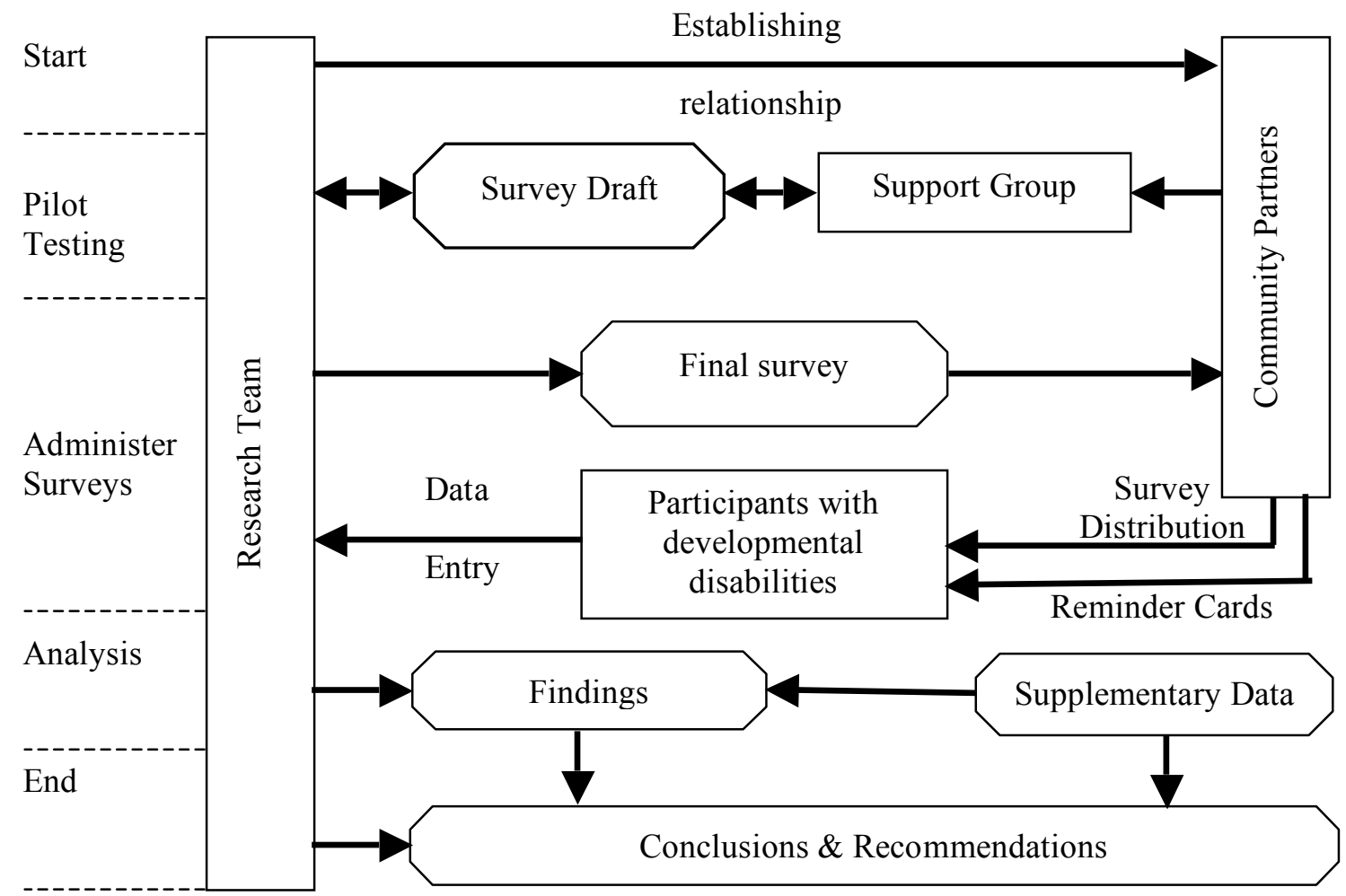

Figure 1: Research Design 


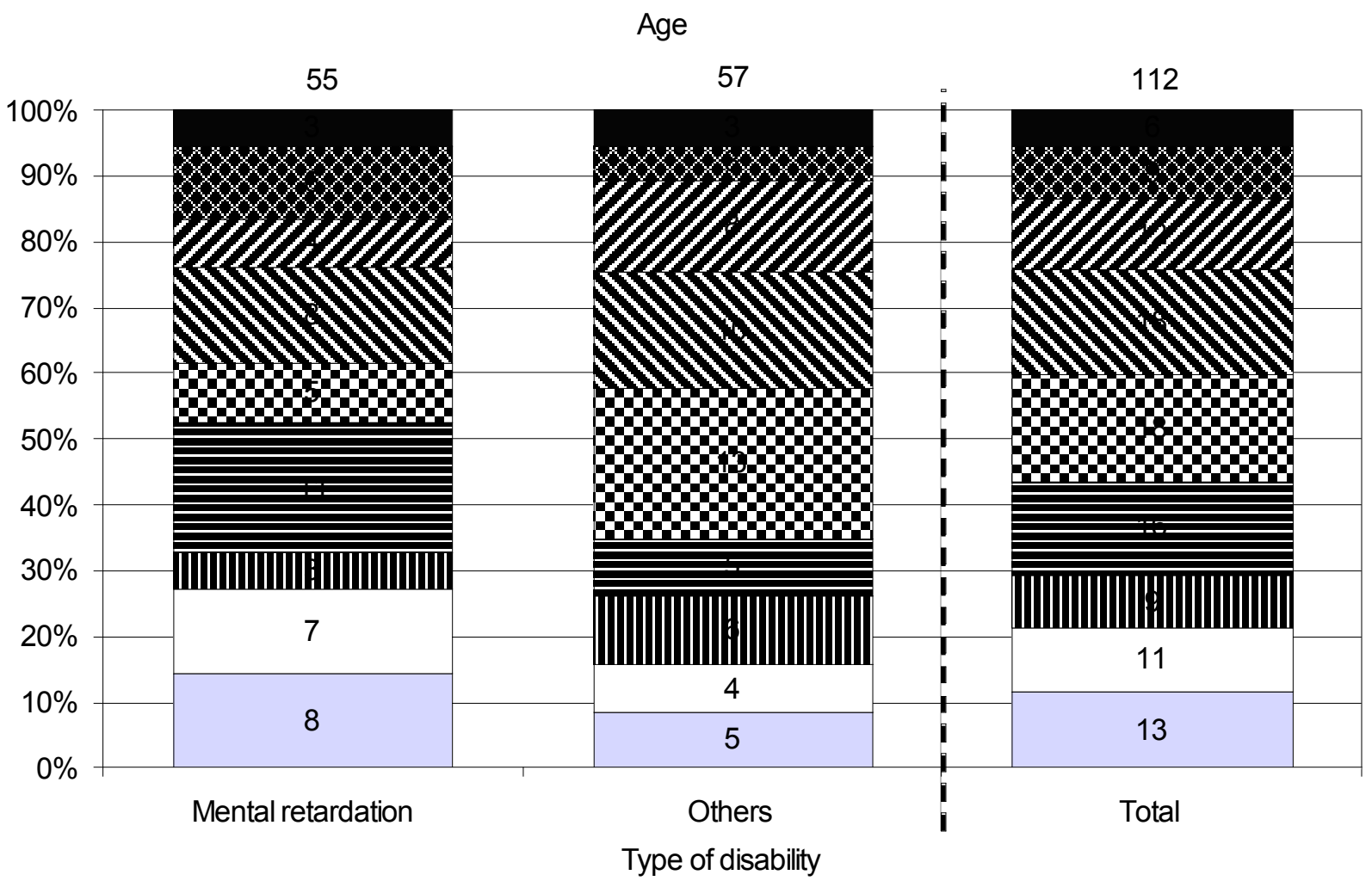

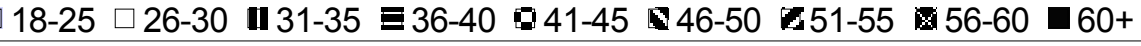

Figure 2: Sample by Age Group 
How often do you do work trips?

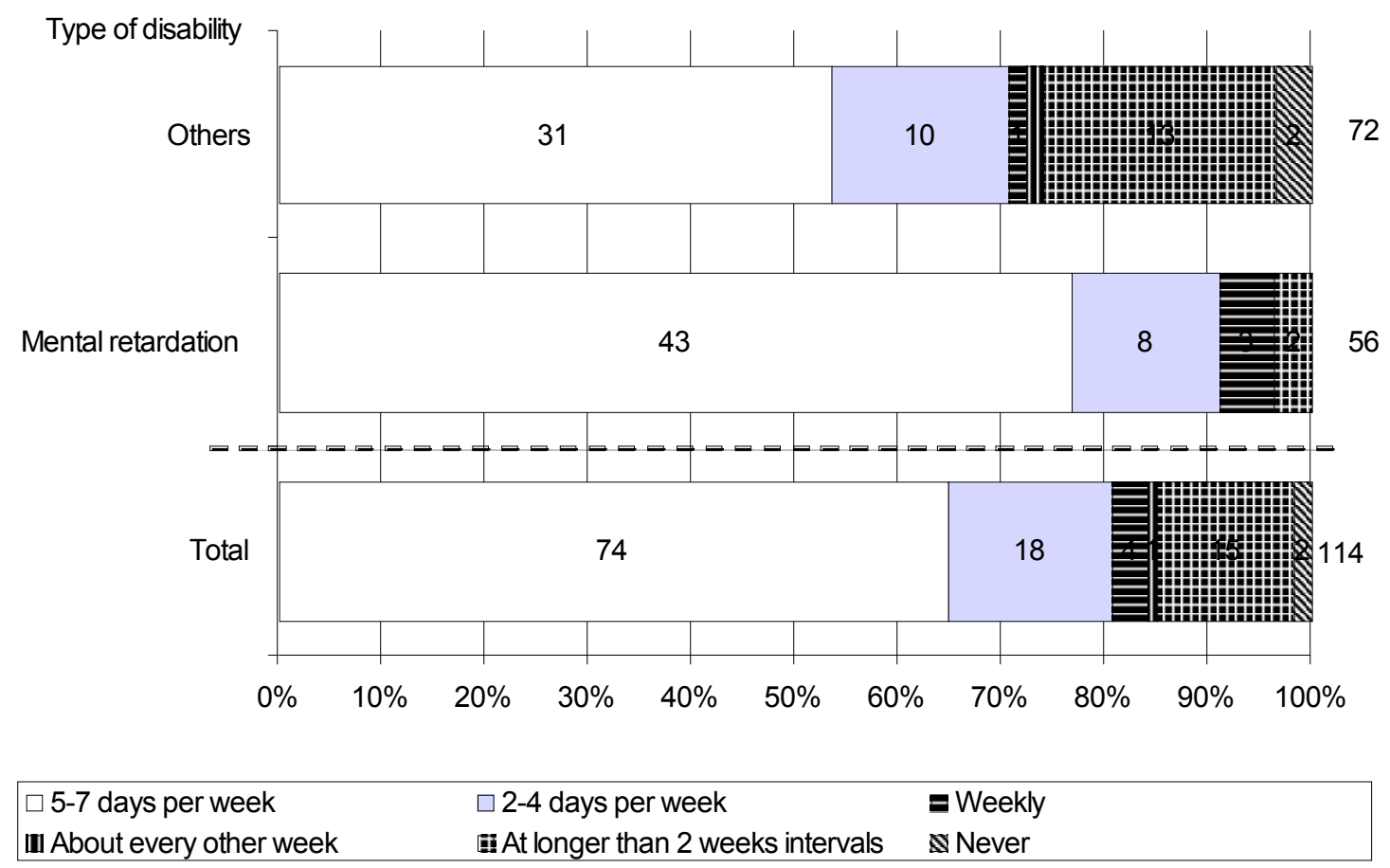

Figure 3: Frequency Work Trips 
How often do you make recreation trips?

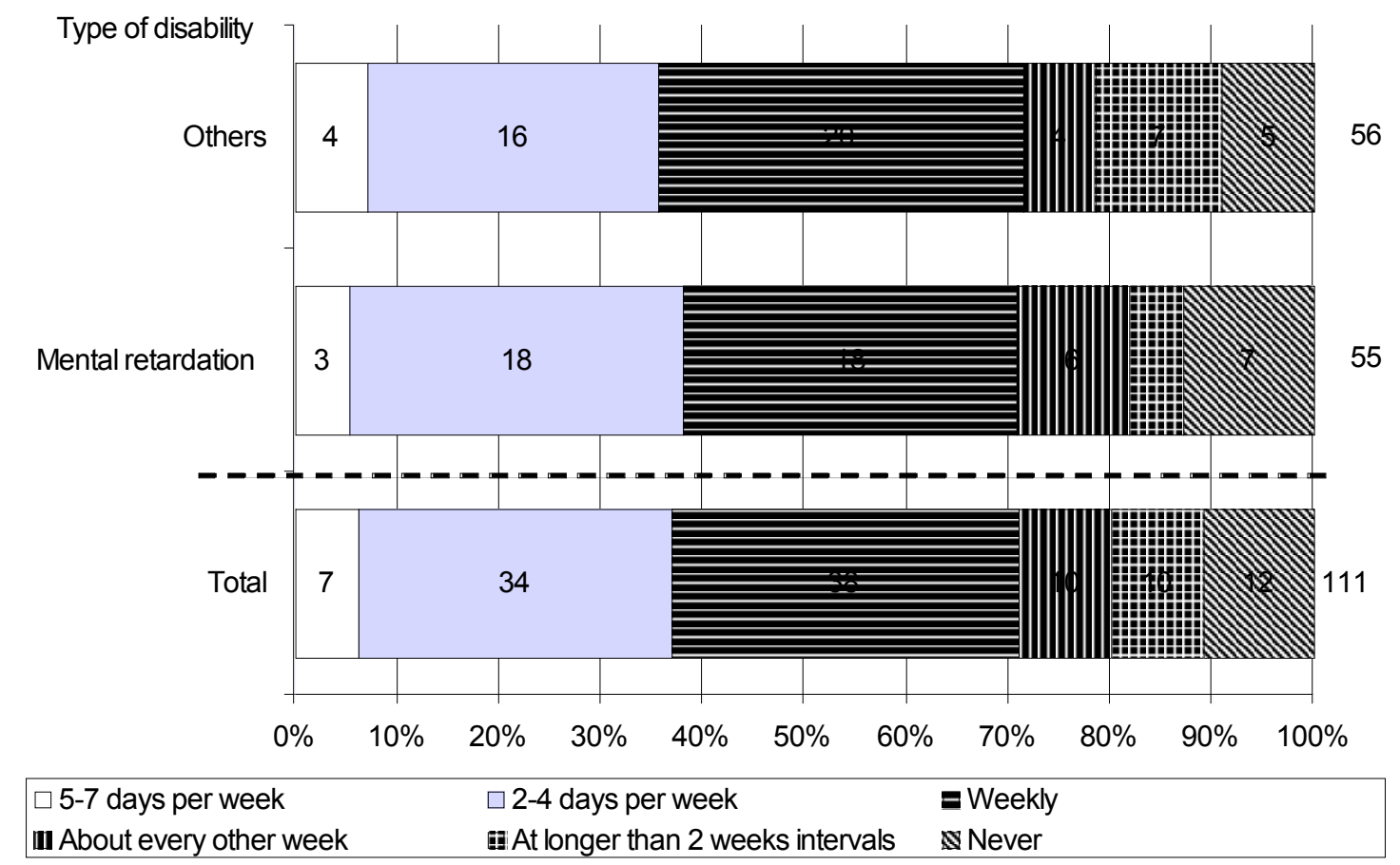

Figure 4: Frequency of Recreational Trips 
How often do you make social trips?

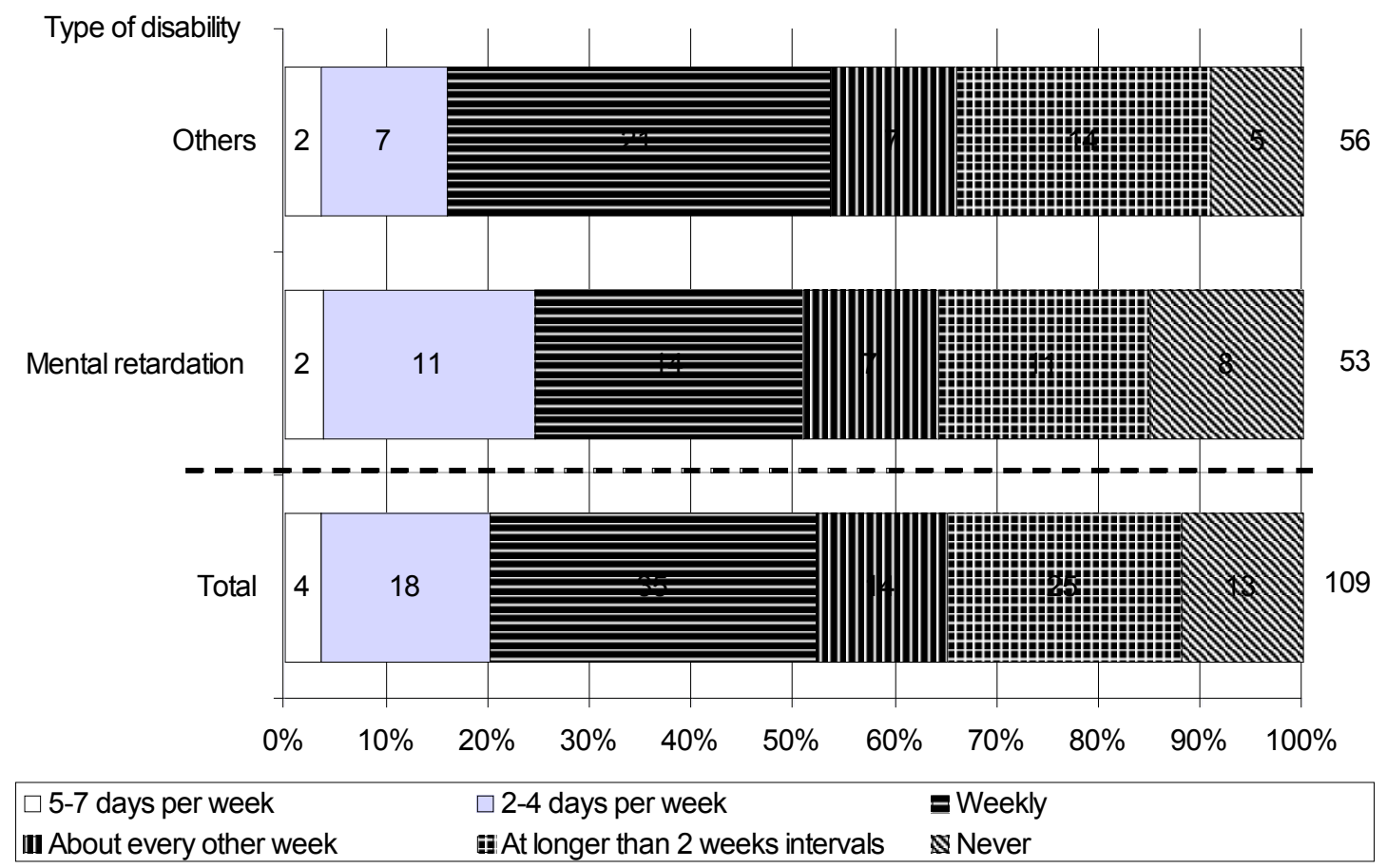

Figure 5: Frequency of Social Trips 